\title{
Price Dispersion When Stores Sell Multiple Goods
}

Nicholas Trachter

$\mathrm{S}$ earch frictions are a prominent departure from the standard style of model we tend to write, which relies on frictionless Walrasian markets. They are not only prominent because they help us construct interesting models where policy can play a particularly important role, but also because search frictions are relatively easy to measure in the data. A large fraction of the literature on search frictions dwells with models of product markets where, for one reason or another, customers face a cost to act in the market (i.e., pay a search or switching cost to switch stores, pay a cost to learn a set of prices, etc.). A well-known result in a large class of models (based on the seminal work of Burdett and Judd [1983]) is that price dispersion for identical goods arises in equilibrium.

The empirical evidence on price dispersion for product markets a good measure of the extent of the friction, as there should be no price dispersion for homogeneous goods in a Walrasian market - is large, mostly documenting dispersion for particular goods in retail markets. The literature abstracts from several important features of retail markets. One of these features is that most stores sell multiple goods, a feature that not only changes the measurement of search frictions, but also opens new avenues for theoretical research, given the scant availability of models of multiproduct pricing, i.e., models where firms price multiple goods simultaneously. In this paper, I review the work of Kaplan et al. (2016) (KMRT from now on), which is a recent study on the empirical properties of price dispersion in a multiproduct setting and provides a model to rationalize it.

- The views expressed in this article are those of the author and do not necessarily represent those of the Federal Reserve Bank of Richmond or the Federal Reserve System. E-mail: nicholas.trachter@rich.frb.org.

DOI: http://doi.org/10.21144/eq1020202 
Most models of price dispersion feature retailers selling a single good. Thus, claims about price dispersion across goods are also claims about dispersion in prices across retailers. However, this correlation across stores and goods does not need to be perfect, for example, if the choice of a price of an individual good is not independent of a retailer's choices of prices for any other goods sold at his store. In fact, if stores sell multiple goods, we can understand whether dispersion arises at the store level or if dispersion arises at the store-good level. Exploring the forces driving price dispersion lets us understand the frictions we need to introduce into our models.

KMRT attempts to provide answers to the origins of price dispersion. Empirically, it does so by exploiting some recently available largescale datasets. The Kilts-Nielsen Retail Scanner (KNRS) dataset provides an ideal laboratory to study price dispersion with multiproduct retailers (i.e., retailers that sell multiple goods). The KNRS provides weekly price and quantity information for around 1.5 million goods a good is defined by its Universal Product Code or UPC - at about 40,000 stores across the United States from 2006 to 2012. The vast amount of information in datasets like the KNRS allows researchers to provide novel insights to the measurement of price dispersion. KMRT finds that there is a large amount of price dispersion for identical goods - standard deviation of 15 percent - and that a large part of this dispersion is due to stores with the same average price level pricing individual goods in persistently different ways. This finding, not shown before in the literature, is coined by the authors as relative price dispersion. A similar feature was found by Gorodnichenko et al. (2015) for stores selling multiple goods in online markets.

In this paper, I review the basics of the empirical findings of KMRT regarding relative price dispersion, and I also provide a review of the basics of the theoretical model the authors develop to explain their empirical findings. The paper is full of robustness exercises (for the empirical analysis) and validation exercises (for the main mechanism that the paper puts forward). The objective of this paper is to introduce the reader to this exciting avenue for research.

\section{RELATIVE PRICE DISPERSION IN THE DATA}

Let $p j s t$ denote the price of good $j=1,2, \ldots, J$ at store $s=1,2, \ldots$, $S$ at week $t$. To make goods comparable (i.e., butter is much cheaper than caviar) it is useful to normalize all prices. With this in mind, let

$$
\hat{p}_{j s t}=\ln p_{j s t}-\frac{\sum_{s} \ln p_{j s t}}{S}
$$


Figure 1 Distribution of Normalized Prices

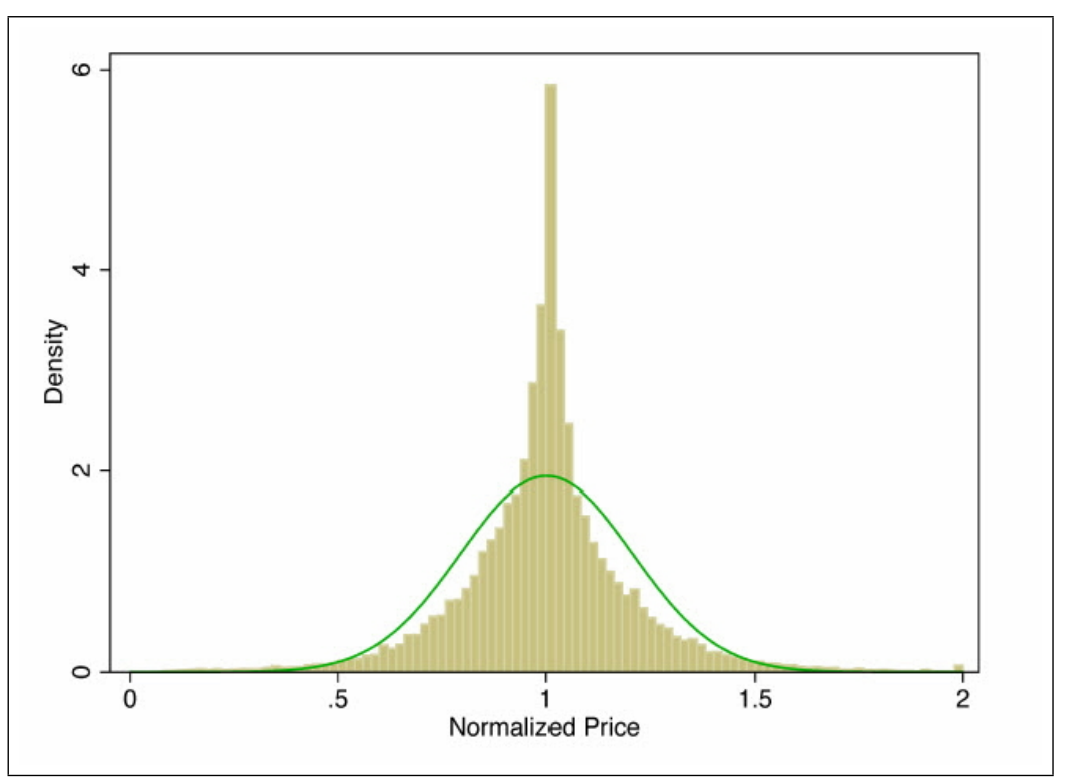

denote the normalized price of a given good in a particular geographical region. ${ }^{1}$ The value $\hat{p}_{j s t}$ measures the $(\log )$ relative price of a good $j$ sold by store $s$ relative to the price of that good sold by every store in the geographical region, at week $t$. For example, if $\hat{p}_{j s t}=0.1$, we have that, at time $t$, good $j$ is 10 percent more expensive in store $s$ than in the other stores in the area. Likewise, when $\hat{p}_{j s t}=-0.1$, we have that the good is 10 percent cheaper at store $s$.

Figure 1 plots the average distribution of normalized prices across all goods, markets, and time periods (the distribution is expenditure weighted), borrowed from Kaplan and Menzio (2015), which uses data from the KNRS dataset. Also, to aid in the analysis, the figure plots the density of a normal distribution with the same mean and variance. As it can be seen, the price distribution exhibits higher kurtosis, with a high concentration of mass close to the mean. More importantly, price dispersion is large, with a standard deviation for normalized prices, $\hat{p}_{j s t}$, of 0.15 .

\footnotetext{
${ }^{1}$ The boundaries of the region define the set of stores to be included and thus define the set $S$.
} 
What explains the extent of price dispersion we observe in the data? How much of the price dispersion that we observe comes from the fact that different stores have different price levels (store component)? How much comes from the fact that stores price the different goods they sell in different ways (store-good component)? How much is transitory, and how much is persistent? Campbell and Eden (2014) noted that for a subsample of the KNRS, the store component does not explain all of the variation. In other words, they noted that some of the variability needs to come from the store-good component. Lewis (2008) observed something similar for the price of the same kind of gasoline at different gas stations. With the aim to decompose price dispersion, we can write the price of good $j$ at store $s$ at week $t$ as

$$
\hat{p}_{j s t}=\hat{y}_{s t}+\hat{z}_{j s t} \text {. }
$$

The term $\hat{y}_{s t}$ accounts for the store component (i.e., the price level of the store) and is defined as $\hat{y}_{s t}=\sum_{j} \hat{p}_{j s t} / J$. The term $\hat{z}_{j s t}$ is the store-good component, and it is defined as a residual: $\hat{z}_{j s t}=\hat{p}_{j s t}-$ $\hat{y}_{s t}$. The store component captures the extent to which a store tends to be more expensive than other stores, regardless of each individual good that it sells, while the store-good component captures variation in relative prices across goods for a particular store.

Furthermore, a statistical model can be posed for each component (i.e. the store and store-good components) in order to understand their persistence. A particularly appealing model is to use an $\operatorname{ARMA}(1,1)$ representation for each component, with the intention of capturing persistent variation with the autoregressive component and transitory variations with the moving average component. Table 1 presents the variance decomposition for the baseline scenario considered in KMRT, which is restricted to the Minneapolis-St. Paul Designated Market Area (DMA), which is roughly consistent with the Minneapolis-St. Paul Metropolitan Statistical Area (MSA). Also, the baseline scenario restricts the analysis to include only 1,000 goods - those with the highest revenue in the DMA.

As the table shows, the standard deviation of normalized prices is 0.153. The standard deviation of the store component is 0.06 , and the standard deviation of the store-good component is 0.141 . In fact, the variance decomposition implies that only 15.5 percent of the variation of prices is explained by the store component, while the rest - 84.5 percent of variance - is explained by the store-good component. On the one hand, the relatively low importance of the store component implies that explanations for price dispersion that follow from store differentials are not that relevant. Standard explanations of the store component 
Table 1 Dispersion in Prices: Persistent and Transitory (from KMRT)

\begin{tabular}{|c|c|c|c|c|c|}
\hline \multirow[b]{2}{*}{ Store component } & \multirow{2}{*}{\multicolumn{2}{|c|}{ Variance }} & \multicolumn{2}{|l|}{ Percent } & Standard Deviation \\
\hline & & & & & \\
\hline Transitory & 0.000 & & 3.2 & & 0.011 \\
\hline Fixed plus persistent & 0.004 & & 96.8 & & 0.059 \\
\hline Total Store & & 0.004 & 100.0 & 15.5 & 0.060 \\
\hline Store-good component & & & & & \\
\hline Transitory & 0.013 & & 64.1 & & 0.113 \\
\hline Fixed plus persistent & 0.007 & & 35.9 & & 0.084 \\
\hline Total store-good & & 0.020 & 100.0 & 84.5 & 0.141 \\
\hline Total & & 0.023 & & 100.0 & 0.153 \\
\hline
\end{tabular}

Note: The left column presents the cross-sectional variances of UPC prices, as well as the store and store-good components separately. The middle columns present the decomposition of this variance into persistent and transitory components. The right column presents the cross-sectional standard deviations.

are those that stem from heterogeneous cost structures across stores and heterogeneity across stores with respect to the amenities provided to shoppers (i.e., differentials in the shopping experience that can be translated into price differentials). On the other hand, the relatively high importance of the store-good component implies that we need to focus our attention on theories that explain why stores with the same overall price level price individual goods in different ways.

Around 65 percent of the variance of the store-good component is explained by its transitory components, while 35 percent of the variance is explained by highly persistent components. The literature offers compelling theories of transitory differences in the price of the same good across equally expensive stores. For instance, according to the theory of intertemporal price discrimination (see, e.g., Conlisk et al. 1984; Sobel 1984; and Menzio and Trachter 2015a), sellers find it optimal to occasionally lower the price of a particular good in order to discriminate between low-valuation customers who are willing to do their shopping at any time during the month and high-valuation customers who need to make their purchases on a specific day of the month. As different sellers implement these occasional price reductions at different times, the equilibrium may feature short-term differences in the price of the same good across equally expensive stores. According to the inventory management theory (see, e.g., Aguirregabiria 1999), a seller finds it optimal to increase the price of a good as the inventory of the good falls and to lower the price when the inventory of the good is replenished. As different sellers have different inventory cycles, the 
Table 2 Robustness (from KMRT)

\begin{tabular}{|c|c|c|c|c|c|c|c|c|}
\hline \multirow[b]{3}{*}{ Store } & \multicolumn{2}{|c|}{ Low price } & \multicolumn{2}{|c|}{ High price } & \multicolumn{2}{|c|}{$\begin{array}{c}\text { Low } \\
\text { durability }\end{array}$} & \multicolumn{2}{|c|}{$\begin{array}{c}\text { High } \\
\text { durability }\end{array}$} \\
\hline & $\mathrm{Sd}$ & $\begin{array}{l}\text { Dec/ } \\
\%\end{array}$ & $\mathrm{Sd}$ & $\begin{array}{l}\text { Dec/ } \\
\%\end{array}$ & $\mathrm{Sd}$ & $\begin{array}{l}\text { Dec/ } \\
\%\end{array}$ & $\mathrm{Sd}$ & $\begin{array}{l}\text { Dec/ } \\
\%\end{array}$ \\
\hline & \multirow{3}{*}{0.024} & \multirow{3}{*}{8.7} & \multirow{3}{*}{0.025} & \multirow{3}{*}{15.6} & \multirow{3}{*}{0.013} & \multirow{3}{*}{4.0} & \multirow{3}{*}{0.027} & \multirow{3}{*}{27.9} \\
\hline Transitory & & & & & & & & \\
\hline $\begin{array}{l}\text { Fixed plus } \\
\text { persistent }\end{array}$ & & & & & & & & \\
\hline $\begin{array}{l}\text { Total Store } \\
\text { Store-good }\end{array}$ & 0.082 & 20.6 & \multirow[b]{2}{*}{0.130} & 15.9 & 0.063 & 19.3 & 0.051 & 19.4 \\
\hline Transitory & 0.122 & 57.4 & & 77.0 & 0.103 & 64.0 & 0.077 & 55.8 \\
\hline $\begin{array}{l}\text { Fixed plus } \\
\text { persistent }\end{array}$ & 0.105 & 42.6 & 0.071 & 23.0 & 0.077 & 36.0 & 0.069 & 44.2 \\
\hline \multirow[t]{3}{*}{ Total store-good } & 0.161 & 79.4 & 0.148 & 84.1 & 0.129 & 80.7 & 0.103 & 80.6 \\
\hline & \multicolumn{2}{|c|}{ Unilever } & \multicolumn{2}{|c|}{ Coca-Cola } & \multicolumn{2}{|c|}{ State: MN } & \multicolumn{2}{|c|}{$\begin{array}{l}\text { County: } \\
\text { Hennepin }\end{array}$} \\
\hline & $\mathrm{Sd}$ & $\begin{array}{l}\mathrm{Dec} / \\
\%\end{array}$ & $\mathrm{Sd}$ & $\begin{array}{l}\mathrm{Dec} / \\
\%\end{array}$ & $\mathrm{Sd}$ & $\begin{array}{l}\text { Dec/ } \\
\%\end{array}$ & $\mathrm{Sd}$ & $\begin{array}{l}\text { Dec/ } \\
\%\end{array}$ \\
\hline \multicolumn{9}{|l|}{ Store } \\
\hline $\begin{array}{l}\text { Transitory } \\
\text { Fixed plus }\end{array}$ & 0.035 & 27.4 & 0.030 & 15.5 & 0.011 & 2.5 & 0.015 & 6.2 \\
\hline persistent & 0.058 & 72.6 & 0.070 & 84.5 & 0.070 & 97.5 & 0.058 & 93.8 \\
\hline $\begin{array}{l}\text { Total Store } \\
\text { Store-good }\end{array}$ & 0.068 & 21.3 & 0.076 & 26.2 & 0.071 & 17.6 & 0.060 & 12.5 \\
\hline Transitory & 0.101 & 60.9 & 0.106 & 68.9 & 0.120 & 60.9 & 0.128 & 64.4 \\
\hline $\begin{array}{l}\text { Fixed plus } \\
\text { persistent }\end{array}$ & 0.081 & 39.1 & 0.071 & 31.1 & 0.096 & 39.1 & 0.095 & 35.6 \\
\hline Total store-good & 0.130 & 78.7 & 0.127 & 73.8 & 0.154 & 82.4 & 0.159 & 87.5 \\
\hline
\end{tabular}

Note: This table presents a set of robustness exercises developed in KMRT. In particular: the low- and high-price samples, the low- and high-durability samples, the Unilever and Coca-Cola samples, and alternative definitions of a market (state of Minnesota and Hennepin County).

equilibrium may feature short-term differences in the price of the same good across equally expensive stores. However, little has been made in the literature to understand the persistent component that, following KMRT, I will describe as relative price dispersion. Before moving to the description of a simple theory of relative price dispersion, I want to discuss some of the robustness exercises in terms of the variance decomposition results. These exercises will shed light on why existing theories cannot explain relative price dispersion. The robustness exercises are provided in Table 2 .

High- and low-price goods. A potential explanation for relative price dispersion is managerial inattention (Ellison et al. 2015). According to this story, equally expensive stores may set persistently different 
prices for the same good because managers choose to not pay much attention to the price of low-ticket items. With this in mind, KMRT looks at relative price dispersion for low-price and high-price goods. The low-price subsample features more relative price dispersion than the full sample: the store-good component accounts for 79 percent of the overall variance of prices, of which the persistent components account for 43 percent. The high-price subsample features less relative price dispersion than the full sample, but relative price dispersion is still a substantial fraction of overall price dispersion. Hence, relative price dispersion is not only a feature of low-price, low-revenue goods and thus is unlikely to be entirely due to managerial inattention.

Goods from a single distributor. Another possible explanation for relative price dispersion is that equally expensive stores set persistently different prices for the same good because they have better or worse relationships (and, hence, are charged lower or higher prices) with the wholesaler. With this in mind, KMRT decomposes price dispersion for a subset of products produced and distributed by a single wholesaler. If relative price dispersion is caused by different retailer-wholesaler relationships, relative price dispersion should be absorbed by the store component when we restrict attention to products from a single wholesaler. The paper considers two subsamples of goods: goods produced by Coca-Cola and by Unilever. For both samples of goods, the overall degree of price dispersion is very similar to the degree of price dispersion in the baseline sample. However, the fraction of variation that is due to the store component is somewhat larger: 21 percent for Unilever and 26 percent for Coca-Cola, compared with 16 percent for the baseline. This is consistent with the hypothesis that some part of price dispersion is due to different relationships between particular stores and particular distributors. However, for both of these distributors, the vast majority of price dispersion is due to the store-good component, and, of this, the persistent parts account for 39 percent (Unilever) and 31 percent (Coca-Cola). Thus, relative price dispersion exists even when only considering goods from the same distributor and so is not only driven by heterogeneity in distributional relationships.

Low- and high-durability goods. Another natural explanation for relative price dispersion is shelf management. Some stores may keep perishable goods on their shelves for longer and, for this reason, sell them at systematically lower prices, while other stores may remove perishable goods sooner and, for this reason, sell them at systematically higher prices. To evaluate this story, KMRT decomposes price dispersion separately for two subsamples of goods: low-durability goods (i.e., perishable goods) and high-durability goods. Even though the two subsamples contain very different sets of products, the overall 
decomposition of price dispersion is quite similar. For both subsamples, the store component accounts for approximately 20 percent and the store-good component for 80 percent of the cross-sectional variance of prices. For both subsamples, the transitory part accounts for roughly two-thirds and the persistent part for roughly one-third of the cross-sectional variance of the store-good component of prices. These findings suggest that relative price dispersion is unlikely to be a phenomenon caused by different styles of shelf management for perishable goods. Indeed, relative price dispersion turns out to be slightly more important in the subsample of goods that are less perishable.

Markets. The baseline analysis focused on a single geographic region, the Minneapolis-St. Paul DMA. To show that the results do not depend on the particular level of geographic aggregation, Table 2 also considers alternative levels of geographic aggregation for the definition of a market. In particular, it reports the variance decomposition when we use a broader definition of market (the state of Minnesota) and a narrower definition of a market (Hennepin County, which is contained in the Minneapolis-St. Paul DMA). All findings are robust to switching to either of these alternative levels of aggregation.

\section{A MODEL OF RELATIVE PRICE DISPERSION}

In this section, I consider the model developed and used in KMRT to explain the concept of relative price dispersion. The model is a variation of Burdett and Judd (1983), which is the workhorse model to explain equilibrium price dispersion across stores selling a single homogeneous good. In KMRT, the model is extended to allow for multiple goods (in particular, two goods) and to allow for heterogeneity in customer shopping behavior. The latter assumption follows from the observation in the data that there is heterogeneity in the number of stores that customers visit. This assumption is critical in order to obtain relative price dispersion.

Consider a market populated by homogeneous sellers and heterogeneous buyers who trade two goods (i.e., good 1 and good 2). Specifically, the market is populated by a measure $s>0$ of identical sellers. Every seller is able to produce each of the two goods at the same constant marginal cost, normalized to zero. Every seller chooses a price for good $1, p_{1}$, and a price for good 2, $p_{2}$, so as to maximize his profits, taking as given the distribution $H\left(p_{1}, p_{2}\right)$ of the vector of prices across sellers. Denote as $F_{i}(p)$ the fraction of sellers whose price for good $i \in\{1,2\}$ is smaller than $p$. Here, $F_{i}(p)$ refers to the distribution of

prices for good $i \in\{1,2\}$. Similarly, let $G(q)$ denote the fraction of 
sellers whose prices $p_{1}$ and $p_{2}$ sum up to less than $q$. $G(q)$ refers to the distribution of basket prices.

On the other side of the retail market, there is a measure 1 of buyers. A fraction $\mu_{b} \in(0,1)$ of buyers are of type $b$ and a fraction $\mu_{c}=1-\mu_{b}$ of buyers are of type $c$, where $b$ stands for busy and $c$ stands for cool. A buyer of type $b$ demands one unit of each good, for which he has valuation $u_{b}>0$. A buyer of type $c$ demands one unit of each good, for which he has valuation $u_{c}$, with $u_{b}>u_{c}>0$. More specifically, if a buyer of type $i \in\{b, c\}$ purchases both goods at the prices $p_{1}$ and $p_{2}$, he attains a utility of $2 u_{i}-p_{1}-p_{2}$. If a buyer of type $i \in\{b, c\}$ purchases one of the two goods at the price $p$, he attains a utility of $u_{i}-p$. If a buyer of type $i \in\{b, c\}$ does not purchase any of the goods, he attains a utility of zero.

In the retail market, trade is frictional. Buyers cannot purchase from just any seller in the market, as each buyer only has access to a small network of sellers. In particular, a buyer of type $b$ can access only one seller with probability $\alpha \in(0,1)$ and two sellers with probability $1-\alpha$. Similarly, a buyer of type $c$ can access only one seller with probability $\alpha$ and two sellers with probability $1-\alpha$. A buyer who can only access one seller is referred to as a captive buyer, and a buyer who can access multiple sellers is referred to as a noncaptive buyer. The authors interpret these restrictions on the buyers' access to sellers as physical constraints (i.e., sellers the buyer can easily reach) rather than as informational constraints (i.e., sellers of which the buyer is aware). Moreover, it is assumed that a buyer of type $b$ must always make all of his purchases from just one of the sellers in his network. In contrast, a buyer of type $c$ can purchase different goods from different sellers in his network. Again, the authors interpret this assumption as heterogeneity in the buyer's ability or willingness to visit multiple stores when shopping.

Notice that the model is static, as in Burdett and Judd (1983). The equilibrium price distribution resulting from the model should be interpreted as a long-term outcome. Indeed, in a repeated version of the model, it can be seen immediately that sellers would have nothing to gain from changing their prices over time. Moreover, in the presence of any type of adjustment costs, sellers would face a loss from changing their prices over time. Thus, in a repeated version of the model, sellers would keep their prices constant. Then, under this interpretation of the model, we should compare the equilibrium price distribution to the distribution of the persistent component of sellers' prices. 


\section{Equilibrium with Relative Price Dispersion}

Consider an equilibrium in which some sellers have a basket price $q$ greater than $u_{b}+u_{c}$ and some sellers have a basket price smaller than $u_{b}+u_{c}$ and greater than $2 u_{c}$. Those sellers pricing a basket above $u_{b}+u_{c}$ will only sell baskets to busy shoppers, while those sellers pricing between $2 u_{c}$ and $u_{b}+u_{c}$ will sell baskets to busy shoppers and one good to cool shoppers. KMRT refers to this type of equilibrium as a discrimination equilibrium, as in this equilibrium some sellers set their prices so as to discriminate between the high-valuation buyers who must purchase all the goods in the same location and the low-valuation buyers who can purchase different goods in different locations.

Sellers pricing baskets above $u_{b}+u_{c}$. Notice that it is not optimal for any seller in this region to set the price of either individual good above $u_{b} .{ }^{2}$ Then, because no price is strictly above $u_{b}$ also no price is equal or below $u_{c}$. As a result, sellers in this region do not sell goods to cool shoppers. Moreover, because no price is above $u_{b}$, the price of the basket $q=p_{1}+p_{2}$ is below $2 u_{b}$. Then, busy shoppers buy the basket of goods at these sellers. Because in this region only busy shoppers buy, and because they buy the basket of goods at price $q$, any combination of prices for good 1 and good 2 that give the same basket price $q$ gives the same profits to the seller. Then, in this region, there will be indeterminacy of prices of good 1 and good 2, and the equilibrium will pin down the distribution of basket prices.

In this region, the profits of a seller are given by

$$
S_{1}(q)=\mu_{b}[\alpha+2(1-\alpha)(1-G(q))] q .
$$

The seller is in the network of $\mu_{b} \alpha$ captive buyers of type $b$. A captive buyer of type $b$ purchases both goods from the seller with probability 1 , since $q<2 u_{b}$. The seller is also in the network of $\mu_{b} 2(1-\alpha)$ noncaptive buyers of type $b$. A noncaptive buyer of type $b$ purchases both goods from the seller with probability $1-G(q)$, which is the probability that the second seller in the buyer's network has a basket price greater than $q$. Finally, the seller is in the network of some buyers of type $c$, but these buyers do not buy from this seller.

The highest basket price, $q_{h}$, on the support of $G$ equals $2 u_{b}$. To see why, suppose that $q_{h}$ is strictly smaller than $2 u_{b}$. In this case, the profit for a seller with a basket price of $q_{h}$ is then equal to $\mu_{b} \alpha q_{h}$, as this seller is the one with the highest basket price in the economy and, hence, only sells to captive buyers of type $b$. However, if the seller sets a basket price of $2 u_{b}$, he attains a profit of $\mu_{b} \alpha 2 u_{b}$, as the seller still

\footnotetext{
${ }^{2}$ To show this, it suffices to show that if a seller prices a good above $u_{b}$, there is a deviation to price at $u_{b}$ that increases profits.
} 
only sells to captive buyers of type $b$. Since $\mu_{b} \alpha q_{h}<\mu_{b} \alpha 2_{u} b$, it follows that the seller with a basket price of $q_{h}$ is not maximizing his profit, and, hence, this cannot be an equilibrium. Hence, $q_{h}=2 u_{b}$.

Second, the support of $G$ in this region is an interval $\left[q^{*}, q_{h}\right]$. To see why, suppose that the support of $G$ has a gap between the basket price $q_{0}$ and the basket price $q_{1}$. In this case, a seller with a basket price of $q_{0}$ attains a profit of $\mu_{b}\left[\alpha+2(1-\alpha)\left(1-G\left(q_{0}\right)\right)\right] q_{0}$. A seller with a basket price of $q_{1}$ attains a profit of $\mu_{b}\left[\alpha+2(1-\alpha)\left(1-G\left(q_{1}\right)\right)\right] q_{1}$. Since $G$ has a gap between $q_{0}$ and $q_{1}, G\left(q_{0}\right)=G\left(q_{1}\right)$ and the seller with a basket price of $q_{0}$ makes the same number of trades as a seller with a basket price of $q_{1}$ but enjoys a lower profit per trade. Therefore, the seller with a basket price of $q_{0}$ does not maximize his profit, and, hence, this cannot be an equilibrium.

It is now possible to solve for the distribution $G$ in this region. At any point in the support of $G$ it has to be the case that sellers attain the same profit. That is, $S_{1}(q)=S^{*}$. We can obtain $S^{*}$ by evaluating $S_{1}(q)$ at $q^{*}=2 u_{b}$, which provides that $S^{*}=\mu_{b} \alpha 2 u_{b}$ (given that $G\left(2 u_{b}\right)=1$ ). Then, we have that

$$
\mu_{b}[\alpha+2(1-\alpha)(1-G(q))] q=\mu_{b} \alpha 2 u_{b} \text { for all } q \in\left[q^{*}, 2 u_{b}\right] .
$$

Solving this equation with respect to $G(q)$ provides an expression for the equilibrium distribution of basket prices above $u_{b}+u_{c}$,

$$
G(q)=1-\frac{\alpha}{2(1-\alpha)} \frac{2 u_{b}-q}{q} \text { for } q \in\left[q^{*}, 2 u_{b}\right] .
$$

Sellers pricing baskets between $2 u_{c}$ and $u_{b}+u_{c}$. As it happened for sellers pricing above $u_{b}+u_{c}$, no seller would choose here to price individual goods above $u_{b}$. Because of this, and because the basket price $q$ of any seller in this region satisfies $2 u_{c}<q \leq u_{b}+u_{c}$, we have that in this region sellers price one good below $u_{c}$ and one good between $u_{c}$ and $u_{b}$. As a result, sellers in this region sell baskets to busy shoppers and one good to cool shoppers. Say that the cheap good that the seller sells to the busy shopper is good $i$. Then, the profit of a seller in this region is given by

$$
\begin{aligned}
S_{2 i}\left(q, p_{i}\right)= & \mu_{b}[\alpha+2(1-\alpha)(1-G(q))] q \\
& +\mu_{c}\left[\alpha+2(1-\alpha)\left(1-F_{i}\left(p_{i}\right)\right)\right] p_{i} .
\end{aligned}
$$

Even though we will not show it here, this expression makes use of the fact that $G(q)$ does not have mass points and $F_{i}(p)$ does not have mass points over the interval $\left(0, u_{c}\right]$.

An important result is that, for all $p \in\left[0, u_{c}\right]$, the fraction of sellers charging less than $p$ for good 1 is exactly the same as the fraction of sellers charging less than $p$ for good 2. That is, $F_{1}(p)=F_{2}(p)=F(p)$ 
for all $p \in\left[0, u_{c}\right]$. Because of this, the profit of a seller pricing in this region is symmetric in the two goods. That is,

$$
S_{21}(q, p)=S_{22}(q, p)=S_{2}(q, p) .
$$

Although I will not provide a proof here, the idea is intuitive. If $F_{1}(p)>$ $F_{2}(p)$ for $p \in\left(p_{0}, p_{1}\right)$, with $0 \leq p_{0}<p_{1} \leq u_{c}$, then a seller posting the prices $(p, q-p)$ in this region would be better off posting the prices $(q-p, p)$ instead. In fact, the seller trades the basket of goods to the same number of type $b$ buyers and at the same price by posting either $(q-p, p)$ or $(p, q-p)$. However, by posting $(q-p, p)$ rather than $(p, q-p)$, the seller trades the cheaper good to more type $c$ buyers even though he charges the same price for it. Hence, if $F_{1}(p)>F_{2}(p)$ for $p \in\left(p_{0}, p_{1}\right)$, all sellers posting the prices $(p, q-p)$ in this region would be better off switching the price tags of the two goods until $F_{1}(p)=F_{2}(p)$.

A key result is that the profit of a seller pricing in this region attains its maximum at $S^{*}$ for all basket prices $q$ and prices of the cheaper good $p$ such that $q$ is in the interval $\left[q_{l}, u_{b}+u_{c}\right]$ and $p$ is in the interval $\left[p_{l}, u_{c}\right]$, where $q_{l}$ denotes the lower bound on the support of the price distribution of baskets and $p_{l}$ denotes the lower bound on the support of the price distribution of an individual good. That is, $S_{2}(q, p)=S^{*}$ for all $(q, p)$ such that $q \in\left[q_{l}, u_{b}+u_{c}\right]$ and $p \in\left[p_{l}, u_{c}\right]$. The proof of the statement is available in KMRT and follows the same strategy used in Menzio and Trachter (2015a). The idea of the proof is to show that if profits are not constant for all $(q, p)$ such that $q \in\left[q_{l}, u b+u c\right]$ and $p \in\left[p_{l}, u c\right]$, there are either gaps in the support of the distribution of $G$ over the interval $\left[q_{l}, u b+u c\right]$ or gaps in the support of the distribution $F$ over the interval $\left[p_{l}, u c\right]$. In turn, if there are gaps in the support of one of the two distributions, there are some sellers who could increase their profits by either increasing the price of the basket or by increasing the price of one of the cheaper good.

We can now solve for the lowest basket price $q^{*}$ posted by sellers pricing baskets above $u_{b}+u_{c}$, for the marginal distribution $G(q)$ for sellers pricing baskets below $u_{b}+u_{c}$, and for the marginal distribution $F(p)$ of prices among sellers in this region. Using that profits are maximized at $S^{*}$, and given that it has to be the case that $S_{2}(q, p)=S^{*}$ for $q \in\left[q_{l}, u_{b}+u c\right]$ and $p \in\left[p_{l}, u_{c}\right]$, we can use $S_{2}\left(u_{b}+u_{c}, u_{c}\right)=S^{*}$ to obtain

$\mu_{b}\left[\alpha+2(1-\alpha)\left(1-G\left(u_{b}+u_{c}\right)\right)\right]\left(u_{b}+u_{c}\right)+\mu_{c}\left[\alpha+2(1-\alpha)\left(1-F\left(u_{c}\right)\right)\right] u_{c}=S^{*}$.

Similarly, for a seller pricing a basket at $q^{*}$ (recall that $q^{*}>u_{b}+u_{c}$ ) with both individual prices strictly above $u_{c}$ and below $u_{b}$, it is also the case that attains the maximized profit $S^{*}$,

$$
\mu_{b}\left[\alpha+2(1-\alpha)\left(1-G\left(q^{*}\right)\right)\right] q^{*}=S^{*} .
$$


Notice that the fraction of sellers with a basket price smaller than $q^{*}$ is the same as the fraction of sellers with a basket price smaller than $u_{b}+u_{c}$, i.e., $G\left(q^{*}\right)=G\left(u_{b}+u_{c}\right)$. Also, notice that the fraction of sellers who charge less than $u_{c}$ for good 1 is half of the fraction of sellers with a basket price smaller than $q^{*}$, i.e., $F\left(u_{c}\right)=G\left(q^{*}\right) / 2$. Using these two observations together with equation (2) and equation (3) provides

$$
\begin{aligned}
& \mu_{b}\left[\alpha+2(1-\alpha)\left(1-G\left(u_{b}+u_{c}\right)\right)\right]\left(u_{b}+u_{c}\right)+ \\
& \mu_{c}\left[\alpha+2(1-\alpha)\left(1-G\left(q^{*}\right) / 2\right)\right] u_{c} \\
& =\mu_{b}\left[\alpha+2(1-\alpha)\left(1-G\left(q^{*}\right)\right)\right] q^{*} .
\end{aligned}
$$

We can solve this equation to find an expression for $q^{*}$ (using equation (1) to obtain $G\left(q^{*}\right)$ ),

$$
q^{*}=\frac{2 \alpha\left(1+u_{c} / u_{b}\right)+\alpha\left(\mu_{c} / \mu_{b}\right)\left(u_{c} / u_{b}\right)}{4 \alpha-(2-\alpha)\left(\mu_{c} / \mu_{b}\right)\left(u_{c} / u_{b}\right)} 2 u_{b} .
$$

We can use the fact that we figured out that profits are constant for all $(q, p)$ such that $q \in\left[q_{l}, u_{b}+u_{c}\right]$ and $p \in\left[p_{l}, u_{c}\right]$ to obtain an expression for $G(q)$. Notice that a seller posting prices $\left(p_{1}, p_{2}\right)$ such that $p_{2} \in\left(u_{c}, u_{b}\right]$ and $q=p_{1}+p_{2} \in\left[q_{l}, u_{b}+u_{c}\right]$ attains the same profit as a seller posting prices $\left(u_{c}, u_{b}\right)$,

$$
\begin{gathered}
\mu_{b}[\alpha+2(1-\alpha)(1-G(q))] q+\mu_{c}\left[\alpha+2(1-\alpha)\left(1-F\left(u_{c}\right)\right)\right] u_{c} \\
=\mu_{b}\left[\alpha+2(1-\alpha)\left(1-G\left(u_{b}+u_{c}\right)\right)\right]\left(u_{b}+u_{c}\right)+ \\
\mu_{c}\left[\alpha+2(1-\alpha)\left(1-F\left(u_{c}\right)\right)\right] u_{c} .
\end{gathered}
$$

Using that $G\left(u_{b}+u_{c}\right)=G\left(q^{*}\right)$, we can solve this last equation to obtain an expression for the distribution of basket prices for $q \in\left[q_{l}, u_{b}+u_{c}\right]$,

$G(q)=G\left(q^{*}\right)-\frac{\alpha+2(1-\alpha)\left(1-G\left(q^{*}\right)\right)}{2(1-\alpha)} \frac{u_{b}+u_{c}-q}{q}$ for $q \in\left[q_{l}, u_{b}+u_{c}\right]$.

Solving the equation $G\left(q_{l}\right)=0$ with respect to $q_{l}$, we find that the lowest price on the support of the distribution of basket prices is given by

$$
q_{l}=\frac{2 \alpha u_{b}}{2-\alpha} \frac{u_{b}+u_{c}}{q^{*}}
$$

Following the same argument as before, a seller posting prices $\left(p_{1}, p_{2}\right)$ such that $p_{1} \in\left[p_{l}, u_{c}\right], p_{2} \in\left(u_{c}, u_{b}\right]$, and $p_{1}+p_{2}=q_{l}$ attains the same profit as a seller posting prices $\left(u_{c}, q_{l}-u_{c}\right)$, i.e.,

$$
\begin{aligned}
& \mu_{b}[\alpha+2(1-\alpha)] q_{l}+\mu_{c}[\alpha+2(1-\alpha)(1-F(p))] p \\
& =\mu_{b}[\alpha+2(1-\alpha)] q_{l}+\mu_{c}\left[\alpha+2(1-\alpha)\left(1-F\left(u_{c}\right)\right)\right] u_{c} .
\end{aligned}
$$

Again, using the fact that $F\left(u_{c}\right)=G\left(q^{*}\right) / 2$ and solving the equation with respect to $F(p)$, we find that the distribution of good 1 prices for 
$p \in\left[p_{l}, u_{c}\right]$ is given by

$$
F(p)=\frac{G\left(q^{*}\right)}{2}-\frac{\alpha+2(1-\alpha)\left(1-G\left(q^{*}\right) / 2\right)}{2(1-\alpha)} \frac{u_{c}-p}{p} .
$$

Solving the equation $F\left(p_{l}\right)=0$ with respect to $p_{l}$ provides an expression for the lowest price on the support of the distribution of good 1 prices, which is given by

$$
p_{l}=\frac{\alpha+2(1-\alpha)\left[1-G\left(q^{*}\right) / 2\right]}{2-\alpha} u_{c} .
$$

This completes the characterization of the equilibrium. In this equilibrium, there is a group of sellers who sets a basket price of $q \in\left[q^{*}, q_{h}\right]$ and the prices $p_{1}$ and $p_{2}$ in between $u_{c}$ and $u_{b}$. These sellers trade (with some probability) the basket of goods to buyers of type $b$ and never trade with buyers of type $c$. There is also a group of sellers who set a basket price of $q \in\left[q_{l}, u_{b}+u_{c}\right]$. Half of these sellers set $p_{1}$ below $u_{c}$ and $p_{2}$ between $u_{c}$ and $u_{b}$. These sellers trade (with some probability) the whole basket of goods to buyers of type $b$ and good 1 to buyers of type $c$. The other half of the sellers sets $p_{2}$ below $u_{c}$ and $p_{1}$ between $u_{c}$ and $u_{b}$. These sellers trade (with some probability) the whole basket of goods to buyers of type $b$ and good 2 to buyers of type $c$. There are no sellers who set a basket price of $q$ in the interval $\left(u_{b}+u_{c}, q^{*}\right)$.

The distribution of basket prices $G(q)$ is given by equation (1) for $q \in\left[q^{*}, q_{h}\right]$ and by equation (5) for $q \in\left[q_{l}, u_{b}+u_{c}\right]$. The distribution $G(q)$ is such that the seller's profit from trading the basket of goods to buyers of type $b$ is equal to $S^{*}$ for all $q \in\left[q^{*}, q_{h}\right]$, and it is equal to $S^{*}-\mu_{c}\left[\alpha+2(1-\alpha)\left(1-F\left(u_{c}\right)\right)\right] u_{c}$ for all $q \in\left[q_{l}, u_{b}+u_{c}\right]$. The distribution $G(q)$ has a gap between $u_{b}+u_{c}$ and $q^{*}$. The gap exists because a seller with a basket price of $u_{b}+u_{c}$ trades with both buyers of type $b$ and buyers of type $c$, while a seller with a basket price greater than $u_{b}+u_{c}$ only trades with buyers of type $b$. Therefore, a seller strictly prefers setting a basket price of $u_{b}+u_{c}$ rather than setting any basket price just above $u_{b}+u_{c}$. The distribution of prices for an individual good $F(p)$ is given by equation (7) for $p \in\left[p_{l}, u_{c}\right]$. The distribution $F(p)$ is such that the seller's profit from trading the cheaper good to buyers of type $c$ is equal to $S^{*}-\mu_{b}(2-\alpha) q_{l}$ for all $p \in\left[p_{l}, u_{c}\right]$. The distribution $F(p)$ is not uniquely pinned down for $p \in\left(u_{c}, u_{b}\right]$. Intuitively, this is the case because a seller who charges a price of $p>u_{c}$ for one good only trades that good to buyers of type $b$ together with the other good.

The distribution of price vectors $H$ is not uniquely pinned down. For sellers with a basket price $q \in\left[q^{*}, q_{h}\right]$, there are several distributions $H$ that generate the marginal distribution of basket prices $G(q)$ in equation (1) and thus are consistent with equilibrium. For example, as discussed in KMRT, there is an equilibrium in which, for all $q \in$ 


\section{Figure 2 Equilibrium with Relative Price Dispersion (from KMRT)}

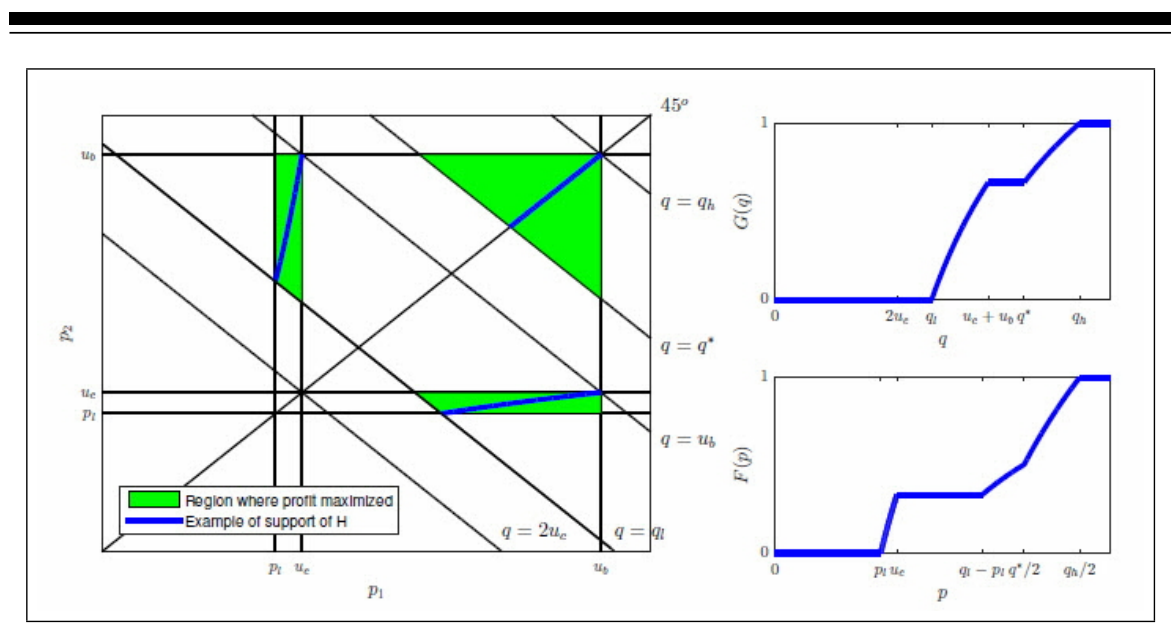

Notes: This figure shows the possible range of the support of the joint distribution $H(p 1, p 2)$, the shape of the cumulative distributions $G(q)$, and an example of the shape of the cumulative distribution $F(p)$ in the discrimination equilibrium.

$\left[q^{*}, q_{h}\right]$, there are $G^{\prime}(q)$ sellers with a basket price of $q$, and each of them posts the prices $(q / 2, q / 2)$. For sellers with a basket price $q \in\left[q_{l}, u_{b}+\right.$ $\left.u_{c}\right]$, there are again several distributions $H$ that generate the marginal distribution of basket prices $G(q)$ in equation (5) and the marginal distribution of individual good prices $F(p)$ in equation (7) that are consistent with equilibrium. For example, there is an equilibrium in which, for all $p \in\left[p_{l}, u_{c}\right], 2 F^{\prime}(p)$ sellers have a basket price of $\phi(p)$, $F^{\prime}(p)$ sellers post the prices $(p, \phi(p)-p)$, and $F^{\prime}(p)$ sellers post the prices $(\phi(p)-p, p)$, where

$$
\begin{gathered}
\phi(p)= \\
\frac{\left[\alpha+2(1-\alpha)\left(1-G\left(q^{*}\right)\right)\right]\left(u_{b}+u_{c}\right)}{\left[\alpha+2(1-\alpha)\left(1-G\left(q^{*}\right)\right)\right]+2\left[\alpha+2(1-\alpha)\left(1-G\left(q^{*}\right) / 2\right)\right]\left(u_{c}-p\right) / 2} .
\end{gathered}
$$

A graphical representation is provided in Figure 2 .

To conclude the analysis, it is necessary to provide necessary and sufficient conditions for the existence of this equilibrium. The equilibrium exists if and only if

$$
\frac{\mu_{c}}{\mu_{b}}>\frac{3 \alpha-2}{(2-\alpha) u_{c} / u_{b}}-1, \frac{\mu_{c}}{\mu_{b}} \leq \frac{\alpha-(2-\alpha) u_{c} / u_{b}}{1+(2-\alpha) u_{c} / u_{b}} \frac{1+u_{c} / u_{b}}{u_{c} / u_{b}}
$$


The first condition guarantees that some sellers find it optimal to post basket prices below $u_{b}+u_{c}$. The condition is satisfied if: (i) the market is sufficiently competitive, in the sense that the fraction $\alpha$ of buyers who are in contact with only one seller is smaller than $2 / 3$; or (ii) the relative number of type $c$ buyers, $\mu_{c} / \mu_{b}$, and/or the relative willingness to pay of type $c$ buyers, $u_{c} / u_{b}$, is large enough. The second condition guarantees that no seller finds it optimal to post prices below $2 u_{c}$. The condition is satisfied if: (i) the market is not too competitive, in the sense that the fraction $\alpha$ of buyers who are in contact with only one seller is greater than $2\left(u_{c} / u_{b}\right) /\left(1+2\left(u_{c} / u_{b}\right)\right)$; or (ii) the relative number of type $c$ buyers, $\mu_{c} / \mu_{b}$, and/or the relative willingness to pay of type $c$ buyers, $u_{c} / u_{b}$, is low enough.

The next proposition summarizes the equilibrium discussed in this section.

Proposition 1 The equilibrium exists if the conditions in equation (9) are satisfied. In the equilibrium, the bundle price distribution $G$ is continuous on the support $[q l, u b+u c][[q *, q h]$, where $q *$ is given by equation (4), $q \mathrm{l}$ is given by equation (6), and $q h=2 u b$. For $q \in[q *, q h]$ we have that $G$ is given by equation (1), while it is given by equation (5) for $q \in[q l, u b+u c]$. The distribution of individual prices $F$ is continuous on the interval $[p l, u c]$, where $p l$ is presented in equation (8), and it is given by equation (7).

\section{Discussion}

The equilibrium features price dispersion across sellers, in the sense that some sellers are on average expensive, while some sellers are on average cheap. This property of equilibrium follows immediately from the fact that the distribution of basket prices is nondegenerate. A discrimination equilibrium always features relative price dispersion, in the sense that there is variation across sellers in the price of a particular good at a particular seller relative to the average price charged by that seller. This property of equilibrium follows immediately from the fact that half of the sellers with a basket price $q \in\left[q_{l}, u_{b}+u_{c}\right]$ have a relative price for good 1 that is strictly greater than 1, while the other half of the sellers with a basket price $q \in\left[q_{l}, u_{b}+u_{c}\right]$ have a relative price for good 1 that is strictly smaller than 1 .

Why does relative price dispersion emerge in equilibrium? Competition between sellers drives part of the distribution of basket prices to the region where $q$ is between $2 u_{c}$ and $u_{b}+u_{c}$. A seller with a basket price between $2 u_{c}$ and $u_{b}+u_{c}$ never finds it optimal to post the same price for both goods. Instead, the seller finds it optimal to set the price 
of one good below and the price of the other good above the willingness to pay of type $c$ buyers. That is, a seller with a basket price $q$ between $2 u_{c}$ and $u_{b}+u_{c}$ finds it optimal to follow an asymmetric pricing strategy for the two goods. However, if some sellers post a higher price for good 1 than for good 2, other sellers must post a higher price for good 2 than for good 1, or else there would be some unexploited profit opportunities. That is, the distribution of prices for the two goods must be symmetric across sellers with a basket price $q$ between $2 u_{c}$ and $u_{b}+u_{c}$. The asymmetric pricing strategy followed by each individual seller combined with the symmetry of the price distribution across sellers implies relative price dispersion.

Sellers follow an asymmetric pricing strategy to discriminate between the two types of buyers. The difference in the willingness to pay of type $b$ and type $c$ buyers gives sellers a desire to price discriminate. The difference in the ability of type $b$ buyers and type $c$ buyers to purchase different items in different locations gives sellers the opportunity to price discriminate. In fact, by pricing the two goods asymmetrically, a seller can charge a high average price to the high-valuation buyers who need to purchase all the items together (the buyers of type $b$ ) and charge a low price for one good to the low-valuation buyers who can purchase different items at different locations (the buyers of type $c$ ).

\section{CONCLUDING REMARKS}

In this paper, I reviewed the work by Kaplan et al. (2016). The paper studies price dispersion both empirically and theoretically in setting where firms sell (and price) multiple goods. Empirically, the paper finds that an important fraction of price dispersion for identical goods is due to relative price dispersion. That is, due to the fact that stores with the same overall price level sell individual goods in a persistently different way. The paper then describes a theory that can rationalize its empirical findings, relying on stores that sell multiple goods trying to price discriminate heterogenous customers.

Although the equilibrium is unique, the fact that it is displayed as a discrimination equilibrium depends on the parameters of the model, as described in equation (9). In fact, when the first condition is not satisfied (for example, when the fraction of cool shoppers is low), the equilibrium is such that stores only sell baskets of goods to busy shoppers and, as previously discussed, individual prices would not be pinned down in equilibrium, and thus relative price dispersion would not be a robust prediction of the model. When the first condition is satisfied and the second condition is not satisfied (for example, when the fraction of cool shoppers is moderately high), at least some stores are 
willing to sell both goods to cool shoppers, and thus these stores act as unbundled. Still, relative price dispersion survives here as some stores still price discriminate. Finally, when the fraction of cool shoppers is big enough, the equilibrium becomes completely unbundled, with every store attempting to sell both goods to both cool and busy shoppers.

It is interesting to contrast the type of price discrimination advanced in Kaplan et al. (2016) with intertemporal price discrimination (see, e.g., Conlisk et al. [1984] and Sobel [1984] or, in a search-theoretic context, Albrecht et al. [2013] and Menzio and Trachter [2015b]). The key to intertemporal price discrimination is a negative correlation between a buyer's valuation and his ability to intertemporally substitute purchases. A seller can exploit this negative correlation by having occasional sales. The low-valuation buyers, who are better able to substitute purchases intertemporally, will take advantage of the sales and will end up paying low prices. The high-valuation buyers, who are unable to substitute purchases intertemporally, will not take advantage of the sales and will end up paying high prices. In contrast, this theory of price discrimination is based on a negative correlation between a buyer's valuation and his ability to shop in multiple stores. Moreover, while intertemporal price discrimination takes the form of time variation in the price of the same good, this theory of price discrimination takes the form of variation in the price of different goods relative to the average store price. 


\section{REFERENCES}

Aguirregabiria, Victor. 1999. "The Dynamics of Markups and Inventories in Retailing Firms." Review of Economic Studies 66 (April): 275-308.

Albrecht, James, Fabien Postel-Vinay, and Susan Vroman. 2013. "An Equilibrium Search Model Of Synchronized Sales." International Economic Review 54 (May): 473-93.

Burdett, Kenneth, and Kenneth L. Judd. 1983. "Equilibrium Price Dispersion." Econometrica 51 (July): 955-69.

Campbell, Jeffrey R., and Benjamin Eden. 2014. "Rigid Prices: Evidence From U.S. Scanner Data." International Economic Review 55 (May): 423-42.

Conlisk, John, Eitan Gerstner, and Joel Sobel. 1984. "Cyclic Pricing by a Durable Goods Monopolist." Quarterly Journal of Economics 99 (August): 489-505.

Ellison, Sara Fisher, Christopher M. Snyder, and Hongkai Zhang. 2015. "Costs of Managerial Attention and Activity as a Source of Sticky Prices: Structural Estimates from an Online Market." Mimeo, Massachusetts Institute of Technology.

Gorodnichenko, Yuriy, Viacheslav Sheremirov, and Oleksandr Talavera. 2015. "Price Setting in Online Markets: Does IT Click?" Federal Reserve Bank of Boston Working Paper 15-1 (January).

Kaplan, Greg, and Guido Menzio. 2015. "The Morphology Of Price Dispersion." International Economic Review 56 (November): $1165-1206$.

Kaplan, Greg, Guido Mezio, Leena Rudanko, and Nicholas Trachter. 2016. "Relative Price Dispersion: Evidence and Theory." Federal Reserve Bank of Richmond Working Paper 16-02 (January).

Lewis, Matthew. 2008. "Price Dispersion and Competition with Differentiated Sellers." Journal of Industrial Economics 56 (September): 654-78.

Menzio, Guido, and Nicholas Trachter. 2015a. "Equilibrium Price Dispersion Across and Within Stores." National Bureau of Economic Research Working Paper 21493 (August).

Menzio, Guido, and Nicholas Trachter. 2015b. "Equilibrium Price Dispersion with Sequential Search." Journal of Economic Theory 160 (December): 188-215. 
Sobel, Joel. 1984. "The Timing of Sales." Review of Economic Studies 51 (July): 353-68. 